\title{
Exploring Wordless Feedback Mechanisms in an EAP course in an English-medium University: An Ethnographically-oriented Approach
}

Osei Yaw Akoto ${ }^{1 *}$ and Benjamin Amoakohene ${ }^{2}$

${ }^{1}$ Lecturer, Department of English, Kwame Nkrumah University of Sciences and Technology, Ghana

${ }^{2}$ Assistant Lecturer, Department of General and Liberal Studies, University of Health and Allied Sciences, Ghana.

Corresponding Author: Osei Yaw Akoto, E-mail: oseiyaw.akoto@yahoo.com

ARTICLE INFORMATION ABSTRACT

Received: September 06, 2020

Accepted: October 18, 2020

Volume: 2

Issue: 4

DOI: 10.32996/jeltal.2020.2.4.6

\section{KEYWORDS}

worded feedback, wordless

feedback, product-centered

feedback, feedback
Feedback is considered an integral part of the writing process. It has thus engendered the attention of scholars in discourse analysis, applied linguistics, language education, composition and rhetoric studies, and English for Specific Purposes. This attention, however, is heavily tilted towards worded feedback, at the expense of wordless feedback. Thus, this study explored the use of wordless feedback mechanisms in an EAP course in an English-medium university in Ghana. Thousand eight hundred and ninety-nine scripts of students' essays, and interviews with academics and students constituted the datasets for the study. By doing a qualitative content analysis, we extracted wordless feedback codes from the scripts. The study yielded that teachers used tick, ring, vertical lines, arrows, question marks, carets, and underline as feedback mechanisms. The responses from the teachers and students on the use of these codes indicated that there were variations at three levels: inter-teacher, inter-student and teacher-student, which resulted to miscommunication in the feedback system. The study calls for a standardized feedback code, and education of teachers and students on this system of feedback for effective teaching and learning.

\section{Introduction}

Students' rights: teacher's responsibility and vice versa. This epigrammatic slogan appears appropriate considering the 'contract' between teachers and students in the teaching-learning process. It is the right of a student to be taught, and this right arguably remains the responsibility of the teacher. While the teaching proceeds, it remains the responsibility of the teacher to assess the students, hence right of student to assessment. Assessment which is "the senior partner in teaching and learning' (Biggs \& Tang, 2011, p. 221) is considered central in writing pedagogy. When students fulfill their part of this academic contract, by producing an essay for the teacher, the onus again lies on the teacher to evaluate, grade and provide feedback (Jujunia, 2015). A section of 'Children's Right' charter of University of Cape Coast (UCC) Primary School sums this up: "I have a right to handover my written assignments for marking. This means, my work will be promptly marked and immediate feedback given me to enable me do my corrections".

Providing feedback on students' essays thus becomes a 'must' not a 'may' to the teacher, most especially in English for Academic Purposes (EAP) or what Todd (2003) terms Teaching English for Academic Purposes (TEAP). Todd (2003) renames the concept because he thinks that it is more student-oriented and that 'student learning is the end goal' ( $p$. 148). Jujunia (2015), therefore, intimates: 'It is the students' right to obtain response to their essays.' (p. 1). Stern's (2008) comment on feedback or response in the context of teen blogs becomes useful in academic writing as well. Stern (2008, p. 111) maintains:

'Lack of feedback is especially disheartening to those who put considerable effort into the appearance of the personal home page or the language of the blog. The feeling that one has been heard, that one matters in a greater context, is impeded when authors receive no or little feedback'.

K C AL-KINDI CENTER R D FOR RESEARCH AND Your gavelOPMENT Your gateway to world-class research
Published by Al-KindiCenter for Research and Development. Copyright (c) the author(s). This is an open access article under CC BY license (https://creativecommons.org/licenses/by/4.0/) 
Todd (2003) outlines six mutually non-exclusive approaches in teaching EAP: inductive learning, process syllabuses, authenticity, technology, team teaching and negotiated syllabuses. He situates feedback within the last approach and argues that feedback helps to 'promote learner autonomy' (p. 151). Teachers are, therefore, advised not to downplay the usefulness of feedback because it is 'a key element of the scaffolding provided by the teacher to build learner confidence and the literacy resources to participate in target communities' (Hyland \& Hyland, 2006, p. 83).

Research on feedback in students' writing has a long history, and this stresses its usefulness in writing pedagogy. But undue attention has been given to worded feedback at the expense of 'wordless feedback'. It has been argued that gestures and speech are 'semantically and pragmatically co-expressive; and gestures and speech are synchronous' (Anderson, et al: 2004). This gesture-speech argument is extended to writing as well. Hence while worded feedback is mapped to speech, wordless feedback is linked to gestures. It can therefore be noted that 'worded and wordless feedbacks, like gestures and speech, are semantically and pragmatically co-expressive'. Although worded feedback has been explored across genres and disciplines, same cannot be said of wordless ones.

Consequently, the present study explores the use of wordless feedback mechanism in an EAP course in an English-medium university in Ghana, complemented by an ethnographically-oriented approach (Hyland, 2009). The present study sought to 'identify the current practices of giving and using feedback' (Hampton-Lyons \& Chen, 1999, p. 1) in an EAP course in an English medium-university in Ghana. Specifically, the study seeks to:

a. find out the forms of wordless feedback,

b. find out from examiners their rationale behind the use of the wordless feedback,

c. find out from students their 'insider community understandings' (Hyland, 2011, p. 196) of the wordless feedback codes in their marked essays.

The study generally provides useful information on the feedback practices in Ghana. One academic admitted that the wordless feedback comparatively is not the best however, "it is better than none as it is chosen out of convenience given the huge number of scrips an individual lecturer has to mark within a restricted time frame. If you like you can describe it as feedback of necessity".

In the remaining part of the paper, we focus on the scope of the study, the concept of feedback, and the methods employed. These are followed by analysis and discussion, and then conclusion.

\subsection{The Study's Scope}

The present study, as has already been indicated, focuses on wordless feedback mechanisms in students' essays from a Ghanaian public university. We grouped the essays into two based on the absence or presence of a feedback, hence, feedbacked and non-feedbacked essays. Out of the total scripts that were examined for this study, only one was found to be non-feedbacked. Feedbacked scripts involved all scripts that had either writings or 'markings' by the examiners as forms of feedback. Given, the focus of this study, only scripts that had wordless feedbacks were considered. Although grades are considered part of feedback (Underwood \& Tregidgo, 2006; Jujunia, 2015), the paper does not consider the scores as feedback. Hence, a non-feedbacked script is the one which apart from the issue mentioned does not have any form of 'ink annotation' from the examiners.

The study adopts a text-oriented ethnographic approach (Hyland, 2005, 2009) whereby the textual analysis is complemented by the views of the 'feedback' producers (teachers) and consumers (students). The study considers any 'deliberate' markups (except the grades) provided by the teachers on the scripts as a feedback. The markups were obvious considering that the examiners used red or green pen, while the students used either black or blue ink. The study undertakes a descriptive (not prescriptive) analysis of feedbacks in the EAP course in an English-medium university in Ghana. Some studies (e.g. Jujunia, 2015) for a reason known to the researchers limited themselves to only marginal and end comments at the expense of medial or in-text comments with the excuse that 'many of these are simply symbols or codes which focus on language inaccuracies and corrections' (Jujunia, 2015, p. 9).

The literature on feedback suggests two forms of feedback based on the timing (Sommers, 1982). There is a feedback that is provided on drafts in the writing process. Bitchener et al. (2010), for instance, observed that feedback is provided after a student has provided a draft. The aim of this feedback is to help improve the ongoing text or composition. This kind is what 
has engaged the attention of researchers on feedback (see Jujunia, 2015). This type of feedback, which may be called, process-oriented feedback, may serve a two-pronged purpose: to help improve the current text and the future writing tasks of the students (Van Horne, 2011, Hamp-Lyons \& Chen, 1999). But the last purpose is the sole aim of the next feedback which is usually provided on completed essays submitted for grading and assessment. Since, the text has been finally submitted for grading, feedbacks provided on them do not aim at bettering the text, but the future writing tasks of the student writer. This type is termed post-essay feedback or 'product-centered feedback' (Underwood \& Tregidgo, 2006). Hamp-Lyons and Chen (1999) suggest some features of this type of feedback. One, student hardly take notice of this kind of feedback ones they see their grades since their response to the teachers' feedback will not improve their grades. Finally, teachers do not require revised version of the graded work. These factors, as observed by Hamp-Lyons and Chen (1999), influence students' attitude towards this type of feedback. That notwithstanding, the present study is limited to the second type as it remains a nearneglect phenomenon in feedback-in-student-writing studies.

Generally, studies on feedback focus on at least one of these themes: a) the nature and location of teacher written feedback commentary; b) the pragmatic intent of teacher written feedback commentary; c) the linguistic resources investigated, type of feedback (Straub, 1997, Hamp-Lyons \& Chen, 1999). Prior research into feedback practices in students' essays has focused on worded feedback (Ashwell, 2000; Bitchener, Young \& Cameron, 2005; Paulus, 1999), leaving the wordless ones unstudied although they constitute a part of the feedback repertoire of teachers. Information on feedback symbols abound. Wordless feedback mechanism has varied nomenclature. Some guides call it keys, symbols, system, codes. Several manuals on writing or writing guides give attention to this all-important subject matter. More so, individual teachers create, design or develop their own feedback keys for their student use. For instance, McCord (2012) expressed an effort to help students to interpret his corrective feedback. Wolpert-Gawron (2013) provides what may be called the Twelve Commandments in providing feedback. The seventh commandment enjoins teachers to develop keys for providing wordless feedback:

Create a key of feedback symbols - Identify the most common errors that you predict you will see. Develop a key of symbols that you can use in the margins instead of writing in sentences or bullets. This will require students to translate as well, which embeds the lesson even further.

Probably in her obedience to Wolfpert-Gawron (2013) seventh commandment, Peters (n.d.) provided comprehensive keys for feedback. But before the symbols are given to the students the following preamble is given:

I will use these symbols to provide feedback to you on your work. These are common problems that I see in my students' writing, so be sure and have these symbols with you as you are writing and reviewing your graded work!

The keys in Peters' system converge and diverge with some other existing ones. The Chicago Manual classifies the symbols or keys into operational, typographical and punctuation signs. A critical overview of the existing system reveals that the signs are either purely symbols, or letters or alpha-symbolic (letters plus symbols). The choice of the code may be informed by individual, institutional or disciplinary preferences.

In their paper, Anderson et al. (2004) found attentional markings appearing in the forms of circles, underlines, checks, arrows, ticks and tracing of slide contents. They argued that teachers use these annotations when using digital ink in lecture presentation. Although they did not consider these as feedback, they are worth citing in this study as all the identified forms by Anderson et al. (2004) were found to be used a feedback in students writing in the present study. Anderson et al. (2004) contend that these feedbacks are difficult to comprehend acontextually. Context, in their view is not defined yet the identified wordless feedbacks are not conventionalized or standardized and therefore are not used in teacher-teacher discourse in the Department. Besides inconsistency were found in the way these markings were used by the examiners. Thus, students will find it difficult to understand these as one of the student interviewees recounted: "When I see them I don't worry myself so much about them as I don't understand and more as no clues are provided to understanding them"

Feedback is central in teaching and assessment, especially in writing-related courses. This means that it is regardless of level (undergraduate or postgraduate), discipline, genre etc. This study however is limited to a first year course because it is observed that first years as 'new entrants' or novice-of-novice into the university or higher educational discourse community needs feedback more than anybody else (McInnis \& James, 1995; McInnis, James, \& Hartley, 2000). 


\section{Feedback as a Concept}

Feedback has been variously and severally conceptualized and this is evidenced by its multiple labels: handwritten commentary, response, commentary, comments, etc. It is noted that "written comments need to be an extension of the teacher's voice -an extension of the teacher as reader" (Sommers, 1982, p. 155). Lees (1979) outlined seven modes of feedback - correcting, emoting, describing, suggesting, questioning, reminding, and assigning..." Teacher written feedback is regarded any comments, response, concern, advice, judgment questions or error correction written on students' assignments (Lindsay, 2009; Kaweera \& Usaha, 2008). Feedback ranges from "high order vs. low order" concerns (Keh, 1990), "content" vs. "form" (Searle \& Dillon, 1980), and "local vs. global" issues (Zamel, 1985). Feedback, therefore, focuses on language use, structure, organization, style, content, and presentation, formatting and disciplinary conventions and norms. Feedback is perceived as "a means of channeling reactions and advice to facilitate improvements" (Hyland \& Hyland, 2001, p. 186).

Feedbacks are categorised based on a number of factors: purpose (summative and formative), persons involved (teacher feedback and peer feedback), mode (oral feedback and written feedback), placement (intra-lineal/in-text, marginal, and end, Clark [2007]) and focus (content and form). On focus, Ken (2004) outlines two types of feedback as content and form. The former concerns the macro structure by focusing on conceptual, structural and organizational issues. For instance, it interests itself with the logicality, clarity, sufficiency, coherence, cohesiveness, and the relevance of the information provided. But the latter is interested in correctness by focusing on grammar (mechanics), style and formatting, which is generally the concern of proofreading.

Feedback can also occur in the forms of spoken and/or written. In addition, there is non-verbal feedback. In the non-verbal mode, it can occur in any of the forms discussed by Sekyi-Baidoo (2000) as proxemics, chronemics, oculesics, haptics, kinesics, vocalic, and objectics (see pp. 16-18 for detailed discussion of nonverbal modes of communication). In the written form, nonverbal feedback can occur in wordless forms as in lines, diagrams, pictures, etc. Marks on students' scripts are a kind of feedback (cite works JIS). The last type constitutes the focus of the present study. This was informed by two factors. One is the fact that the literature on feedback has not given needed attention to these 'markups' that serve as feedbacks. The most important reason is the fact that it appeared as the dominant form of feedback in the essays understudied. Hence, we intended to describe them and also find out the views of teachers and students of their use. Sekyi-Baidoo (2000) maintains that nonverbal communication serves triadic purposes: to complement the verbal; to repeat the verbal; and to substitute the verbal. In the case of feedback, one can argue that nonverbal feedbacks are employed as a substitute to the verbal and therefore worth scholarly investigation. He therefore advises: "It is important, as we have realized now, that even as we concentrate on the verbal, we need to learn and use the non-verbal as effectively as possible. They are indispensable" (p. 19).

Feedback plays a key role in language education, particularly in writing. Its usefulness is no respecter of person be it native or nonnative speaker of a language. This is rightly so because it has both teacher-and student-oriented benefits or usefulness. Generally, feedback seeks to provide judgement, comment or evaluation of the text. Thus, the teacher assesses the text and 'declares their judgement' in the form of feedback which can be written or spoken. Specifically, the teacher provides feedback to praise and blame the student of what was rightly and wrongly done. The aim of this is to help the students to improve on their general competence (communicative, pragmatic, discoursal, metadiscoursal, grammatical, disciplinary, linguistic). The teachers aim to raise students' consciousness of the three 'awarenesses' enumerated by Horning (2002) -metarhetorical awareness, metastrategic awareness, and metalinguistic awareness. He mentioned that successful writers employ these awarenesses to better their writings. As experts, teachers through feedback help student writers in their transition from apprenticeship to experthood (Afful, 2009). Murray (1978) notes that feedback draws students' attention to both internal and external revisions, which respectively focus on content and language use.

\section{Methodology}

\subsection{Data Set and Data Collection Procedure}

The setting of the study is University of Cape Coast (UCC), which is the third largest public university in Ghana. It has assessment policy of $40 \%$ for quizzes and $60 \%$ for end-of-semester examination. In the Department of Communication Studies, where the EAP-related programme, called Communicative Skills (CS) is run, the UCC policy is applied with some modifications. For the $40 \%$, two main forms of assessments are practiced. One is that there is a 'General Quiz' (GQ), meant for all undergraduate freshmen and women who read the course. Until the 2015/2016 academic year the marks allocation for the GQ was $10 \%$ while the remaining $30 \%$ is meant for the individual lecturer handling a group in the CS programme. The University policy regarding end-of-semester examination does not allow students to own their examination scripts. Hence, 
even if feedbacks are provided students may not get the opportunity to learn from them. On the contrary, quiz papers are to be marked and recorded and given out to students, and these constituted the dataset for the study.

The rubrics for the examination were 'Write one of the body paragraphs of an essay on the topic: 'How to Promote Peace in Ghana'. The paragraph should be about 120 words'. The papers were marked. Some students came for their scripts but a significant number did not and those uncollected scripts totaling thousand eight hundred and ninety-nine $(1,899)$ constituted the dataset for this research. The second instrument of data collection was interview in a semi-structured format which employed open-ended prompts focused on the observed wordless feedback practices of the lecturer. However, the interviewees were allowed to raise other useful issues. Five 4 lecturers (one each from the four colleges for regular programmes), and 12 students ( 3 from each of the four colleges for regular programmes) were selected. The interviews were conducted with experienced lecturers who had taught the EAP course, and first year undergraduate students who had been given their marked essays. More so, there were also intermittent interviews of both students and lecturers in situations where there were 'information gaps' after the textual analysis. The aim of this follow up interview was to limit authorial speculations. For example, in analyzing the textual data, it was realized that some wordless feedback codes (e.g. underline and circle) were used interchangeably. Some lecturers and students were then interviewed for their views on such cases. The main interviews lasted between five to ten minutes. Both rounds of interviews were conducted one-on-one and audiorecorded. The audio-recorded version was given to a Master of Philosophy student in Department of English for transcription. The ethnographic touch through the interviews offered significant insights which the textual analysis could not reveal (Hyland, 2009).

\subsection{Textual Data Extraction Process}

The scripts were obtained from the General Office of Department of Communication Studies, University of Cape Coast. We gathered them and glanced through each script and extracted the feedbacks in them. While doing this, we grouped the scripts into two categories: feedbacked and non-feedbacked scripts. Any markup in red or green was collected since the examiners used red ink, and the Chief Examiners (or Team Leaders) used green. The students, however, wrote in either blue or black ink. For some of the symbols, we described them for easy analysis. For instance: I wrote "double question marks (??) at the beginning of a paragraph", when I saw two question marks used at paragraph initial. The extracted data or feedbacks were typed and printed. Finally, these, extracted feedbacks were classified and coded for onwards discussion. The responses from teacher and student interviewees are labelled TI and SI with their corresponding numbers such as TII, TI2 and SI1 and SI2 respectively.

\section{Analysis and Discussion}

\subsection{Forms of Wordless Feedback in Students' Essays}

This subsection reports on the findings on the forms of wordless feedback from the scripts examined or studied. As already noted the teachers and students' views employed to complement the textual evidences under each form of wordless feedback.

\subsubsection{Underlines}

Underline constituted part of the wordless feedback mechanism in the assessed essays. The underlines are classified based on the linguistic structure they accompanied: word underlines, phrase underlines, clause underlines, sentence underlines, and paragraph underlines. These indicated the discoursal scope of the feedback. Although previous studies noted underline as a feedback code, they had different imports. Chandler (2003) who found it as an error highlighting strategy. Underline is seen in excerpts of works used in feedback research but in most cases, they are used as probably 'highlighters' because when the structure is underlined it is followed immediately by a written worded feedback (Ferris \& Roberts, 2001; Hamp-Lyons \& Chen, 1999). Hamp-Lyons and Chen (1999) found that teachers underlined a structure and provided a corresponding written feedback, suggesting also that underline and the written feedback performed the same communicative function.

It must be noted that the underline found in this study is different from what has been reported above. The difference lies in the fact in the present study underlines were found to be independently communicative and hence used to semantically and pragmatically communicate a message. The teachers and students thus expressed diverse understandings of the use of underlines as feedback codes.

I underline a structure when I am struck by what the student has written. In fact I do this quite often and so in my scripts underline communicate a message like well done. 
Most of the time I underline if the message is not clear. $\quad T$ TI2

I underline to indicate that the student could have put the expression in a better way. TI3

It implies that there is a problem of expression which makes the written piece hard to understand.

TI4

As for me I used underlines in my marking to mean so many things. Wrong construction. Poor grammar. Poor expression. Ambiguous statement. Lack of clarity. TI5

The views of the teachers are concurrently similar and dissimilar to the understanding of the students.

They either mean the underlined word or statements have been misspelt or there is/are error(s) in them or they are important points that should be noted by the student.

SI1

$\mathrm{SI} 2$

$\mathrm{SI} 3$

$\mathrm{SI} 4$

It means the words were not properly spelt.

see them I try to see what I

1 regard underlines in my essays as grammatical errors or spelling mistake indicators. So when I see the
did wrong.

It means the point or sentence was not complete or does not make meaning or the various punctuation marks were not put at their correct places.

SI6

We can observe from the views of the teachers and students that understand that underline conjure multiple meanings. In effect, it is an ambiguous feedback signal, as there are different interpretations. For instance, for one teacher (TI1), it is used to signal positive feedback, while for the rest for negative feedback (TI2-TI5). The first teacher interviewee said underline communicates 'well done' while one also says 'not clear'. But on the contrary, the students thought that it communicates negatively. Clearly, we see from the views of the students that underlines mean differently to different students. The question, however, is at what point does underline mean a positive or negative feedback as TI1 and SI1 expressed? Further, if it means for instance that the expression is inappropriate, what must the students specifically do, since the underline does not proceed with what must be done? The lack of homogeneity or uniformity in the messages encoded in the underline buttresses the view that wordless feedback is implicit (Mitchell, 1994) and as we know implicitness results in misinterpretation/miscommunication. Furthermore, Williams (2003) mentioned that underline is used in responding to only issues on form, a method of feedback. But evidence from textual observation and interviews (with examiners or teachers) reveal that it is used to comment on both form and content.

\subsubsection{Rings}

We found that ring was also employed by the teachers as part of their feedback to students. It was found that different structures ranging from punctuation marks to paragraph were put in rings. This results in the subtypes of rings based on the structures: punctuation ring, letter ring, morpheme ring, word ring, phrase ring, clause ring, sentence ring and paragraph ring. The study sought to find out from the teachers their rationales behind these varied use of rings. Further the views of students were also solicited on rings in their marked scripts.

That the structure in question is wrongly used or grammatically unacceptable in terms of sentential mechanic such as spelling, punctuation, capitalization, and other similar conventions of usage.

$\begin{array}{ll}\text { Mechanical accuracy -spelling/concord errors } & \mathrm{T} / 2\end{array}$

It is grammatically not acceptable $\quad$ TI3

When I ring a word or structure, I mean to say that the spelling is wrong. $\quad$ TI4

$\begin{array}{ll}\text { The particular structure contains errors. } & \text { TI5 }\end{array}$

The teachers appeared univocal on their views on the use of ring as a feedback code to point to errors that require corrections. The 'negative feedback' from the teachers correlate with the understandings of the students.

That word does not fit into the sentence properly.

SI1

The structures were used wrongly.

$\mathrm{SI} 2$

It means, the word is not properly used in the context or that word is not supposed to be there in that sentence.

It means the word has been spelt wrongly.

$\mathrm{SI} 3$

It means the world is wrong or used out of context.

$\mathrm{SI} 4$

SI5 
A word or statement being circled could mean that the word or statement has errors or is not really needed or shouldn't be brought there. They are used to highlight errors in a sentence.

Generally, the teachers explained that rings are used to indicate mechanical errors, or were used as 'error feedback' (Farid \& Samad, 2012, p. 233) mechanism. Rings are therefore used or employed generally as indirect corrective feedback strategy (Farid \& Samad, 2012). This import is consistent with the guidelines of the Department of Communication Studies on marking students' essays. This instruction generally focuses on the word-level ring. Consequently, it appeared that almost all the students gave meanings for word ring and not those above words, which of course, coincided with that of the teachers. We, therefore sought to find out from the students their views about structures above word that are rang, and one of them expressed that:

I find it confusing because for underlines I consider them to mean that structures are not clear. But when they ring a structure bigger than a word I just ignore it because I just don't understand it. I focus on the marks given that's all.

The confusion expressed by the student is not different from that of the teachers. It suggests lack of clear communication on what ring means when used as feedback mechanisms. Given that feedback aims to help student better their writings (Paulus, 1999), it is important for teachers to resolve this problem to enable students benefit fully from it.

\subsubsection{Caret}

Caret $(\Lambda)$ was also found to be used as a form of feedback in the students' essays. Different kinds were found. We found i. caret only ii. caret in ring iii. caret plus word iv. caret plus punctuation mark and v. caret plus ring on top. Notwithstanding the types, we sought to find out the teachers' and students general view on the use of caret as a feedback code.

$\begin{array}{ll}\text { I normally use the caret sign to indicate omission. } & \text { TI1 }\end{array}$

$\begin{array}{ll}\text { It indicates an omission of a letter in a specific word } & \text { TI2 }\end{array}$

$\begin{array}{ll}\text { There is an omission in the text } & \text { TI3 }\end{array}$

$\begin{array}{ll}\text { It means that a word or something is missing } & \text { TI4 }\end{array}$

$\begin{array}{lr}\text { Something important has been omitted. } & \text { TI5 }\end{array}$

Interestingly, the teachers have a common view on the use of caret as part of their rhetorical choices in their feedback in students' essays. The teachers interviewed noted that caret connotes 'omission' and hence require the students to insert the omitted linguistic structure which, as realized from the essays, ranged from a grapheme to a sentence.

It means a word has to be fixed there

There was an omitted word which was supposed to be introduced

It means there has been an omission

I don't understand so I tend to ignore
$\mathrm{SI} 2$

$\mathrm{SI3}$

$\mathrm{SI} 4$

SI5

Both teachers and students had a shared knowledge on the meaning and communicative function of caret. The only surprising response was one student (SI5) who expressed his lack of understanding of the communicative import of caret. He said that 'I don't understand so I tend to ignore'. We found this relatively strange, striking and, therefore, suggestive. This further implies that what is perceived common knowledge may universally not be common and therefore calls for standardization and education.

\subsubsection{Vertical Lines}

We found that vertical lines (VL) were used as wordless feedback codes. Two main categories of these were found: numberbased classification (single and double VLS ). One teacher expressed that "I use the double when I find the irrelevant materials to be recurring. And so the double use of vertical line is expressive". Meanwhile, a survey of proofreading/editing systems in guides revealed that the single vertical line was used to instruct students to 'insert a space' especially where there is wrong amalgamation of words. The next category is place-based classification which involved sentence initial-end VL and paragraph initial-end VL. 
The general views of teachers and students on the use of VL point to varied understandings among teacher, and students. Variations in the meaning of VL was thus realized at the teacher-teacher, student-student and teacher-student levels, as shown in the responses below.

$\begin{array}{ll}\text { The student has written more than required } & \text { TI1 }\end{array}$

$\begin{array}{ll}\text { The candidate has poor margins } & \text { TI2 }\end{array}$

$\begin{array}{ll}\text { The construction is not cohesive } & \text { TI3 }\end{array}$

$\begin{array}{ll}\text { Irrelevant and should not be in the text } & \text { TI4 }\end{array}$

I use vertical lines when I find a string of sentences in students' essays unintelligible.

he ideas are the same or has been mentioned earlier $\quad \mathrm{SI2}$

$\begin{array}{ll}\text { They are repetitions } & \text { SI4 }\end{array}$

It means your paragraphs are not well arranged in your work $\quad \mathrm{SI5}$

$\begin{array}{ll}\text { The paragraph is totally wrong } & \mathrm{SI}\end{array}$

The divergent views suggest that the use of $V L$ does not yield expected results since the intents of the teachers are not understood by the students. In effect, the encoded messages in VL by the teachers does not lead to effective communication. As noted, corrective feedback is expected to help students better their texts. However, if the students do not get exactly what the teachers seek to direct them to, how do they respond appropriately?

\subsubsection{Ticks}

Tick $(\sqrt{ })$ was utilized by the teachers as part of their feedback mechanism. We found the following subtypes based on their positioning: sentence initial tick, top-of-word tick and end-of-essay tick. Obviously, teachers have an encoded message in the tick, while students have their understanding of these messages. The extracts below represent views are provided from teachers and students.

To indicate good expression; good or valid point made or beautiful construction $\quad$ TI1

$\begin{array}{ll}\text { It indicates good language use } & \text { TI2 }\end{array}$

I use tick to indicate correctness of the point explained $\quad$ TI3

I introduce tick when I find that a student has provided something good

$\begin{array}{ll}\text { A tick to me means what I've written is right } & \text { SI2 }\end{array}$

$\begin{array}{ll}\text { It means you have a right answer to a question } & \text { SI4 }\end{array}$

$\begin{array}{ll}\text { That I might have spelt a word wrong } & \text { SI9 }\end{array}$

It tells me am correct in whatever am trying to put across. $\quad$ SI12

Largely, teachers and students respectively encode and decode tick as a positive feedback mechanism. They both expressed that it is used for a positive appraisal or as a compliment marker. This understanding was common to all the teachers, but to a cross-section of the student interviewees as there was an inter-student and hence teacher-student misunderstandings on the use of tick as feedback symbol. One student opined that tick means 'That I might have spelt a word wrong'. This student is possibly alluding to on-top of words tick. This possibly 'odd' view further supports the highly subjective nature of wordless feedback. The inconsistency in wordless feedback from examiners leads to 'misinterpretation of feedback intention' (HampLyons \& Chen, 1999). This, therefore, calls for the standardization of wordless feedback mechanism.

\subsubsection{Question Marks (QM)}

Grammatically, the question mark signals the end of a sentence and demonstrates that the sentence is a question. The focus of this part rather concerns the pragmatics (rather than the grammar) of question marks as a feedback mechanism. QMs were used as a form of feedback in the scripts. They can be categorized based on number and position. Number-based classification of question marks has five subcategories: single $\mathrm{QM}$, double $\mathrm{QM}$, triple $\mathrm{QM}$, quadruple $\mathrm{QM}$, and pentagonal QM. Under place-based classification, there are subtypes such as paragraph initial, on top of word $Q M$, sentence initial QM, sentence final QM and across- paragraph QM. The number arguably suggests the degree of the communicative function intended by the teachers. 
Question marks are accounted for in feedback by Hamp-Lyons and Chen, (1999) in categorizing feedbacks. Straub (1997) identified six types of feedback: criticism, imperative, advice, open question, and closed question. There was a later model by Hamp-Lyons and Chen (1999) who added two more types as mechanics and?. On?, they wrote "No comments except a '?' usually (emphasis mine) 'don't understand'". The example they cited from their corpus was double question mark (??). I emphasized the word 'usually' because it suggests that the communicative function of QM is context-dependent, as one of the teacher interviewees expressed:

Sometimes I introduce question mark or marks when the information provided by the student is factually inaccurate. For example, if a student says the first president of Ghana was called Kofi Bosuo, I will not even introduce a question mark but marks to show the seriousness of the factual error.

Similar views were also expressed by the other teachers interviewed:

That the sentence is either incomplete or meaningless. So if you like you can consider question mark as a marker of incompleteness of though and or may be meaninglessness.

Incomprehensible, not clear or irrelevant

TI1

$\mathrm{TI} 2$

Clumsy expression. The structure does not make meaning

TI3

For me I use questions to mean several things such as lack of clarity, why use upper case instead of lower case letters and vice versa; poor handwriting TI4

The students also revealed their undertakings of QMs in their assessed essays:

It means the sense or meaning is not well conveyed

$\mathrm{SI3}$

Either there is an omission or incompleteness

$\mathrm{SI} 4$

It means the answer given is not well understood by the marker

SI10

I believe question marks are telling me to be specific

SI11

We observe from the responses of the teachers and students that QM is used as a negative feedback code. Notwithstanding, the students do not obtain a direct instruction on what is required of them. This would be more helpful if the teachers follow up with worded instruction detailing what they require the students to do.

\subsubsection{Parentheses}

Parenthesis and bracket are different -not only in shape but also function; but in this study, parenthesis is used for all 'codes' with similar structures. They are categorized based on the form and the structures around whom they are used. The formbased ones involved round bracket ( ), square bracket [ ], curly bracket \{ $\}$ and oblique bracket or slant // while the structure-based comprised: sentence bracket [ ], paragraph bracket \{\} and //, word bracket ( ) and morpheme bracket ( ). It is really not strange to find different brackets form used for different purposes (Greenbaum, 1996; Rubinstein, 2000). For instance, Rubinstein (2000, p. xvii) used () 'to show alternate wording and parts of speech'; [ ] 'as parentheses within parentheses' and \{\} 'to set off foreign language translations' in his book. The views of teachers and students on the use of brackets as feedback code are provided as follows:

$\begin{array}{ll}\text { Paragraph unnecessary or out of place } & \text { TI1 }\end{array}$

$\begin{array}{ll}\text { Whole paragraph may not be necessary in the passage } & \text { TI2 }\end{array}$

It may mean that paragraph has illogically been introduced into the write-up TI3

That paragraph should be removed because it may not be of relevance to the present discussion.

The paragraph was not supposed to be used $\quad$ SI1

It means those words are to be put in a bracket and not to be left open that way SI7

I don't understand it $\quad$ SI8

That they are not necessary or forms part of an already written idea. SI11

Greenbaum (1996) maintains that parenthesis is used to enclose information which serve the purposes of exemplification, explanation, identification, specification, concession, comment, or justification. But we realized from the views of the teachers and the students that parentheses communicate a message far different from what was outlined by Greenbaum 
(1996). To a large extent, there is teacher-student uniformity on what parentheses means as feedback codes. However, one student expressed that parentheses communicate that 'those words are to be put in a bracket and not be left open that way'. This view reiterates the 'grammar of parenthesis' but as we realize from the teachers view it is diametrically different from what this student expressed. This variation goes to support the fact that the absence of standardization on the meanings of these codes allows multiple interpretations and nuances, which eventually results in miscommunication.

\subsubsection{Arrows}

Arrows such as forward $(\rightarrow)$, backward $(\leftarrow)$, downward $(\downarrow)$ and upward $(\uparrow)$ ones were used by teachers as feedback codes in their commentaries in students' essays. Generally, arrows are used as directional signs that point to the location of an entity. The discourse domain for student writing has shown dissimilar and similar meanings of these 'directional signs'. The arrows function among other things as directives which "instruct the reader to perform an action or to see things in a way determined by the writer" (Hyland, 2005, p. 154). Some perceptions of teachers and students on the use of arrows as feedback code are as follows:

A point is similar to one that has already been made $\quad$ TI1

A construction should be moved to where the arrow points to T12

I sometimes use them to indicate repetition. That is to mean that the ideas linked up by the arrow are the same.

It could mean wrong amalgamation of words which should be properly spaced $\quad$ TI3

To indicate the position of a sentence or idea is wrong.

TI5

Arrows tell me that what l've written is not in the right position

SI7

It means the sentence written has a connection with the first one and they both mean the same thing.

SI9

It means one has repeated the same answer to a question $\quad$ SI10

$\begin{array}{ll}\text { Not necessary } & \text { SI12 }\end{array}$

One teacher remarked that arrow implies that 'a construction should be moved to where the arrow points to', akin to the student who expressed that 'arrows tell me that what I've written is not in the right position'. Asides this, both teachers and students understood arrow differently as shown in their responses. In general, the use of arrows as feedback code lacks two of Wiggins' (2005) criteria of feedback: user-friendliness and consistency. It was realized that it does not generally appear self-explanatory to the students, and also it means different things to different teachers.

\section{Conclusion}

The present study explored wordless feedback codes in undergraduate students' essays. The study has revealed the examiners employed wordless feedback system for 'convenience'. Variability and inconsistencies were found in the use of these systems at three levels: inter-teacher, inter-student and teacher-student. The inconsistency in the wordless system can be likened to the inconsistency in punctuation system and spelling in English prior to it getting standardized (Greenbaum, 1996).

Pedagogically, the study offers a useful insight into the rhetorical choices in feedback practices by EAP teachers in Ghana. We observed that there were variations in the imports of the identified wordless feedback codes among teachers and students; and between teachers and students. It calls for standardizing the wordless feedback system or a shift from that to worded feedback. Hamp-Lyons and Chen (1999) have mentioned that 'for students to make use of feedback, there must be a learning environment that encouraged them to do so'. Two of the teachers interviewed mentioned that they provided the feedback not for student-oriented purpose but for their own use. They noted that the feedback they provided guide them in allocating marks to the various scoring segments: $\mathrm{C}$ for Content; $\mathrm{E}$ for Expression; $\mathrm{O}$ for Organization and MA for Mechanical Accuracy. This reiterates the need for examiners to rather have a two-pronged focus for providing feedback: teacher-oriented and student oriented. An atmosphere must also be created for the students to know that the feedback is for their use and possibly revise the text and resubmit for remarking, although this kind has its own challenges. Hamp-Lyons and Chen (1999) report that because students know that the revision will not affect their grades, they have negatives attitude towards 'product-centered feedback' (Underwood \& Tregidgo, 2006) and hence regard it as 'unnecessary and a total waste of time'. Hamp-Lyons and Chen's (1999) suggestion that "teachers can design a short unit of work for students to 'learn to learn from teacher feedback'" becomes critical in this regard. 
It has implication for design or adoption of wordless feedback system. The system must therefore have a guide as wordless feedback 'is only as good as the guidelines enabling you to use it efficiently' (Rubinstein, 2000, p. xvi). The guide will serve both the teachers and the students as the study revealed that there was the absence of inter-teacher, inter-student, and teacher-student homogeneity regarding the meanings of the wordless feedback codes. Underwood and Tregidgo (2006) maintain that because feedback generally seeks to benefit students, it must possess three major qualities, which are that a feedback must be noticeable to students, acceptable to students and finally understandable by students. Students' response to some of the identified wordless feedback mechanisms indicates that some lack these characteristics. Teachers may provide these feedbacks on the assumption that students know. But as was observed, one can always be wrong with assumptions as one student indicated he did not understand the 'caret' and so ignored it when used as feedback sign. As already reiterated teachers may probably therefore have to shift to worded feedback or standardize the wordless feedback mechanisms or teachers, as recommended by Underwood and Tregidgo (2006), would have to conduct research on which of the feedback mechanism students prefer, as students' interest or needs are paramount in second language teaching (Srichanyachon, 2012).

Based on the findings, it is recommended that other studies be conducted on other universities in Ghana to find out what pertains there as well. If it is realized that the feedback systems there are predominantly wordless, then there would be a need to provide a harmonized wordless feedback system for use in Ghana's institutions of higher learning.

\section{References}

[1] Afful, J. B. A. (2009). Rhetorical analysis of introductions in an undergraduate English Studies course. ESP World. 3(26), 1-28.

[2] Anderson, R. J., Hoyer, C., Wolfman, S. A., \& Anderson, R. (2004). A study of digital ink in lecture presentation. In Proceedings of the SIGCHI conference on Human factors in computing systems (pp. 567-574).

[3] Ashwell, T. (2000). Patterns of teacher response to student writing in a multiple-draft composition classroom: Is content feedback followed by form feedback the best method?. Journal of second language writing, 9(3): 227-257.

[4] Bitchener, J., Young, S., \& Cameron, D. (2005). The effect of different types of corrective feedback on ESL student writing. Journal of Second Language Writing. 14(3), 191-205.

[5] Clark, H., L. (2007). Students' noticing and incorporation of written feedback: A snapshot of ESOL writing instructors' commentary on adult ESOL Students' Essays. Masters thesis, University of Texas at Arlington, USA.

[6] Farid, S. \& Samad, A. A. (2012). Effects of different kind of direct feedback on students' writing. The $8^{\text {th }}$ International Language for Specific Purposes (LSP) Seminar. Procedia- Social and Behavioural Sciences. 66: 232-239.

[7] Freedman, S. W. (1984). The registers of student and professional expository writing: Influences on teachers' responses. In R. Beach, \& L. S. Bridwell (Eds.) New direction in composition research (pp. 334-347). NY: The Guilford Press.

[8] Frankenberg-Gracia, A. (1999). Providing student writers with pre-text feedback. ELT Journal. 53(2): 100-106.

[9] Gborsong, P. A., Afful, J. B. A., Coker, W., Akoto, O. Y., Twumasi, R., \& B., Araba (2015). A needs analysis of undergraduates students of Communicative Skills: The case of tertiary institutions in Ghana. Open Journal of Modern Linguistics. 5: 413-424

[10] Greenbaum, S. (1996). The Oxford English grammar. New York: Oxford University Press.

[11] Hamp-Lyons, L., \& Chen, J. (1999). An investigation into the effectiveness of teacher feedback on student writing. English Language Teaching and Learning, 3, 207-219.

[12] Hyland, K. (2003). Second Language writing. New York: Cambridge University Press. Quarterly 31(2), 315 - 339.

[13] Hyland, K. (2005). Metadiscourse: Exploring interaction in writing. Bloomsbury Publishing.

[14] Hyland, K \& Hyland, F. (2006). Feedback in Second Language writing: Contexts and issues. Cambridge: Cambridge University Press.

[15] Hyland, K. (2009). Academic discourse: English in a global context. A\&C Black.

[16] Hyland, K. (2011). Disciplines and discourses: Social interactions in the construction of knowledge. Perspectives on Writing, 193-214.

[17] Ken, C. K. (2004). An experiment into students' preference for and responses to teacher feedback and its implications for writing teachers. Hong Kong Teachers' Central Journal. 3, 98-115.

[18] Kaweera, C., \& Usaha, S. (2008). The impact of different types of teacher written feedback on EFL university students' writing. KKU Research Journal, 8(2), 83-94.

[19] Leki, I. (1990). Coaching from the margins: Issues in written response. In B. Kroll (Ed.). Second Language writing (pp. 57-68). NY: Cambridge University Press.

[20] Leng, K. T. P. (2014). An analysis of written feedback on ESL students' writing. Procedia-Social and Behavioral Sciences, 123, 389-397.

[21] Merrill, Y. (2000). Anchoring WAC by focusing on rhetorical analysis in first year composition. Language and Learning across the Disciplines. 71-73.

[22] Mitchell, F. (1994). Is There a Text in this Grade? The implicit messages of comments on student writing." Issues in Writing. 6(2): 187195

[23] McCord, M. B. (2012). Exploring effective feedback techniques in the ESL classroom. Language Arts Journal of Michigan, 27(2), 40-45.

[24] McCarthy, M, Matthiessen, C. \& Slade, D. (2002). Discourse analysis: An introduction to applied linguistics. London: Arnold. 
[25] McInnis, C., \& James, R. (1995). First year on campus: Diversity in the initial experiences of Australian undergraduates. Canberra: Australian Government Publishing Service.

[26] McInnis, C., James, R., \& Hartley, R. (2000). Trends in the first year experience in Australian universities (Evaluations and Investigations Programme). Canberra: Centre for the Study of Higher Education, University of Melbourne.

[27] Paulus, T. M. (1999). The effect of peer and teacher feedback on student writing. Journal of Second Language Writing, 8(3), 265-289.

[28] Reid, J. (1994). Responding to ESL students' texts: The myths of appropriation. TESOL Quarterly. 28(2): $273-292$.

[29] Rubinstein, M. (2000). American English Compendium: A portable guidebook for translators, interpreters, writers, editors, and advanced language students. USA: Schreiber Publishing.

[30] Searle, D. \& Dillon, D. (1980). The message of marking: Teacher written responses to student writing at intermediate grade levels. Research in the Teaching of English. 14(3): 233-242.

[31] Sekyi-Baidoo, Y. (2003). Learning and communicating ( $2^{\text {nd }}$ ed.). Accra: Akonta Publications.

[32] Srichanyachon, N. (2012). Teacher written feedback for L2 learners' writing development. Silpakorn University Journal of Social Sciences, Humanities and Arts. 12 (1): 7-17

[33] Stern, S. (2008). Producing sites, exploring identities: Youth online authorship. In D. Buckingham (Ed.) Youth identity and digital media. Cambridge, MA: Massachusetts Institute of Technology. 95-118.

[34] Straub, R. (1997). Students' reactions to teacher comments: An exploratory study. Research in the Teaching of English. 91-119.

[35] Todd, R. W. (2003). EAP or TEAP?. Journal of English for Academic Purposes. 2: 147-156.

[36] Underwood, J. S. \& Tregidgo, A. P. (2006). Improving student writing through effective feedback: Best practices and recommendations. Journal of Teaching Writing. 22(2): 73-97.

[37] Van Horne, S. A. (2011). An activity-theory analysis of how college students revise after writing center conferences. PhD thesis, University of lowa.

[38] Wiggins, G. (2005). Less teaching, more assessing: Learning via feedback. ASCD Conference on Teaching \& Learning, San Francisco.

[39] Williams, J. G. (2003). Providing feedback on ESL students' written assignments. The Internet TESL Journal, 9(10):1-5.

[40] Wolpert-Gawron, H. (2013). Tween crayons and curfews: Tips for Middle School teachers. Routledge.

[41] Zamel, V. (1985). Responding to student writing. TESOL Quarterly. 19(1): 79-101. 